\title{
Patient-reported outcomes in randomized clinical trials: development of ISOQOL reporting standards
}

\author{
Michael Brundage $\cdot$ Jane Blazeby $\cdot$ Dennis Revicki $\cdot$ Brenda Bass $\cdot$ Henrica de Vet \\ Helen Duffy • Fabio Efficace • Madeleine King • Cindy L. K. Lam • David Moher • \\ Jane Scott · Jeff Sloan $\cdot$ Claire Snyder $\cdot$ Susan Yount $\cdot$ Melanie Calvert
}

Accepted: 6 August 2012/Published online: 18 September 2012

(C) The Author(s) 2012. This article is published with open access at Springerlink.com

\begin{abstract}
Purpose To develop expert consensus on a suite of reporting standards for HRQL outcomes of RCTs.

Methods A Task Force of The International Society of Quality of Life Research (ISOQOL) undertook a systematic review of the literature to identify candidate reporting standards for HRQL in RCTs. Subsequently, a web-based survey was circulated to the ISOQOL membership. Respondents were asked to rate candidate standards on a 4-point Likert scale based on their perceived value in reporting studies in which HRQL was a study outcome (primary or secondary). Results were synthesized into draft
\end{abstract}

M. Brundage $\cdot$ B. Bass

Queen's University, Kingston, ON, Canada

J. Blazeby

MRC ConDuCT Hub for Trials Methodology Research, School of Social and Community Medicine,

University of Bristol, Bristol, UK

D. Revicki

Center for Health Outcomes Research, United BioSource

Corporation, Bethesda, MD, USA

H. de Vet

Department of Epidemiology and Biostatistics, EMGO- Institute for Health and Care Research, VU University Medical Center, Amsterdam, The Netherlands

H. Duffy · M. Calvert ( $\square)$

MRC Midland Hub for Trials Methodology Research,

School of Health and Population Sciences, University

of Birmingham, Birmingham, UK

e-mail: m.calvert.1@bham.ac.uk

\section{F. Efficace}

Health Outcomes Research Unit, Italian Group for Adult

Hematologic Diseases (GIMEMA) Data Center, Rome, Italy reporting guidelines, which were further reviewed by the membership to inform the final guidance.

Results Forty-six existing candidate standards for reporting $\mathrm{HRQL}$ results in RCTs were synthesized to produce a 40 item survey that was completed electronically by 161 respondents. The majority of respondents rated all 40 items to be either 'essential' or 'desirable' when HRQL was a primary RCT outcome. Ratings changed when HRQL was a secondary study outcome. Feedback on the survey findings resulted in the Task Force generalizing the guidance to include patient-reported outcomes (PROs). The final guidance, which recommends standards for use in reporting PROs generally, and more specifically, for PROs

\section{King}

Psycho-oncology Co-operative Research Group (PoCoG),

University of Sydney, Sydney, Australia

C. L. K. Lam

Department of Family Medicine and Primary Care, University

of Hong Kong, Pokfulam, Hong Kong

D. Moher

Ottawa Hospital Research Institute, Ottawa, Canada

J. Scott

PRO Center of Excellence, Global Commercial Strategy

Organization, Jansen Global Services, Warrington, UK

J. Sloan

Mayo Clinic Cancer Center, Rochester, MN, USA

C. Snyder

Division of General Internal Medicine, Johns Hopkins Medicine, Baltimore, MD, USA

S. Yount

Northwestern University Feinberg School of Medicine, Chicago, IL, USA 
identified as primary study outcomes, was approved by the ISOQOL Board of Directors.

Conclusions ISOQOL has developed a suite of recommended standards for reporting PRO results of RCTs. Improved reporting of PROs will enable accurate interpretation of evidence to inform patient choice, aid clinical decision making, and inform health policy.

Keywords Reporting - Randomized clinical trials . Quality of life · Patient-reported outcomes · Guidelines

\section{Introduction}

Patient-reported outcome (PRO) data, including healthrelated quality of life (HRQL), from randomised clinical trials (RCTs) may be used to inform clinical decision making, health policy, and reimbursement decisions [1]. PRO data can also be used to meet patients' information needs and to establish treatment preferences [2-6]. However, the collection of PRO data in RCTs is not without costs, including patient and investigator time, and costs associated with questionnaire administration and analysis. For PRO data from RCTs to provide value, the RCTs and PROs need to be well designed, analyzed appropriately, and reported in a way that makes the results accessible and useful to end-users. Inadequate or poorquality reporting limits the valid application of PRO findings in clinical practice [7-9] and can limit synthesis of trial results across studies, using meta-analytic or other synthesis approaches.

Although a number of publications provide guidelines for reporting HRQL outcomes, their implementation in RCTs remains suboptimal. In a recent review of 794 trials that reported HRQL outcomes of biomedical interventions across a range of clinical areas, less than $60 \%$ provided a rationale for the selected outcome measure or a HRQL hypothesis, $33 \%$ did not discuss the HRQL findings within the context of other trials outcomes, and only $28 \%$ provided information on missing HRQL data [10].

Inadequacies in trial reporting in general have been addressed through the development of the Consolidated Standards of Reporting Trials (CONSORT) Statement [11]. This is 'an evidence-based, minimum set of recommendations for reporting RCTs' which 'offers a standard way for authors to prepare reports of trial findings, facilitating their complete and transparent reporting, and aiding their critical appraisal and interpretation.'[11] The original CONSORT statement and its subsequent 'extensions' have been widely endorsed by a number of leading international journals [12]. CONSORT standards specific to PROs, and specifically HRQL, do not currently exist. Recognizing the need for improved reporting of quality of life outcomes, the International Society for Quality of Life Research (ISOQOL) formed a Task Force to lead the development of an official CONSORT extension. This work has been undertaken in collaboration with the CONSORT executive, MRC Midland and ConDuCT Hubs for Trials Methodology Research, leading international journal editors, policy makers, and patient representatives $[11,13,14]$. In this paper, we describe the process that was undertaken by the Task Force to establish an ISOQOL consensus on standards for PRO reporting and report the resultant suite of ISOQOL-recommended standards for PRO reporting. The suite of standards is intended to inform the process of establishing a CONSORT extension for reporting PRO outcomes of RCTs based on broader stakeholder input.

\section{Methods}

Systematic review

A comprehensive literature search was performed in OVID Medline in April 2011 to identify papers about HRQL reporting in RCTs. Search terms were specific to Clinical Trials as Topic/or Randomized Controlled Trials as Topic/and 'Quality of Life'/or HRQL.mp. This search yielded over 4,000 hits; consequently, the search was limited to English-language review articles from 1985 to 2010 .

Medline Search Strategy

1 Clinical trials as topic/or randomized controlled trials $\quad 222,848$ as topic/

2 'Quality of Life'/or HRQL.mp $\quad 89,369$

31 and $2 \quad 4,168$

4 Limit 3 to (english language and 'review articles' and 1,871 year $={ }^{\prime} 1985-2010 `$ )

Careful review of the resulting titles by two authors (MB and $\mathrm{BB}$ ) reduced the number of potentially relevant papers to just over 300; abstracts of these papers were read and full papers obtained where the abstract illustrated potential relevance $(n=53)$. The resultant set of relevant publications was further supplemented with papers found in reference lists from seminal publications as well as those known to experts in the field. A search of the Cochrane database revealed no additional papers. All candidate standards for reporting HRQL outcome data in RCTs were abstracted from the papers identified by the comprehensive review of the literature and tabulated. 
Survey development and administration

A panel of experts forming the ISOQOL Reporting Guidelines Task Force reviewed the candidate reporting standards ('items') to identify redundancies and omissions and created a comprehensive list of items. An online survey was then created based on this list of items. The survey asked respondents to rate the importance of each of the items for guiding the reporting of RCT HRQL results. Two contexts were provided to the respondents: HRQL as either a primary outcome or secondary outcome in a paralleldesign phase III RCT. Respondents were asked to assume that no 'expanded' or secondary publication focused on RCT HRQL findings would be forthcoming. Four response categories were used: (essential, desirable, optional, and rarely necessary to include). An open text field was provided to capture respondents' comments on each item. Finally, the survey requested demographic information relating to participant expertise and experience. Respondents could return to previous items by use of a back button and modify their answers before submitting their final results. Participants were advised that through submission of their results, consent to use their data in this research was implied. Ethical approval for the survey was obtained from the University of Birmingham Ethical Review Board (ERN_11-0225). The survey was developed using Survey Monkey [15].

ISOQOL members were invited via email to participate in the survey that remained open for a 7-week period during which time two email reminders were sent. Descriptive analyses were undertaken using Survey Monkey software statistical functions and Microsoft Excel [16]. Items were ranked according to the percentage of respondents that rated the item as essential. Exploratory subgroup analyses were undertaken to assess variation in response by self-reported expertise. Participants with similar expertise were grouped as follows: HRQL assessment/psychology/ sociology/predominantly in psychometrics (grouped as Psychologist/Social Scientist); frequent journal reviewer/ journal editor (as Journal Editor/Reviewer); clinical trials methods/analysis (as Methodologist); predominantly clinician/clinician-scientist (as Clinician); policy/public health/ regulator/health administrator (as Policy Maker). Because survey participants were able to identify more than one area of expertise, the results of these exploratory analyses are for subgroups that are not mutually exclusive.

\section{Development of the reporting standards}

The results of the survey and free text comments were debated by the Task Force and synthesized into draft reporting standards. Items were placed into categories based on the organization of the existing CONSORT checklist of general reporting standards. Candidate items that were already contained within the main CONSORT 2010 checklist were flagged. The remaining items were grouped by the Task Force into: (1) those reporting standards recommended to be reported in any trial where HRQL is an outcome (primary or secondary) and (2) those recommended for clinical trials in which HRQL is specifically a primary outcome. Similar items were combined, resulting in a reduced draft set of reporting standards that was circulated to ISOQOL members attending the ISOQOL annual conference in Denver, CO in October 2011. Comments were invited through discussion at the Quality of Life in Clinical Practice Special Interest Group Meeting and following an oral presentation by Task Force Members. Further comments were encouraged and received by email. Feedback from the ISOQOL membership at the annual conference resulted in an important shift in the nature of the ISOQOL extension; the extension would no longer be exclusive to HRQL outcomes but rather would recommend reporting standards for all PROs. The final guidance document reflected feedback from both the ISOQOL Board and its broader membership.

\section{Results}

\section{Systematic review}

Fifteen papers by 14 unique first authors were identified that contained guidelines or standards for HQRL reporting in RCTs [7-9, 17-28]. From these papers, 46 HRQL RCT reporting standards were identified (Table 1). Removal of redundant items produced 40 final candidate reporting standards for use as survey items.

\section{Survey results}

There were 161 respondents to the survey, of which 144 (97\%) were confirmed current members of ISOQOL. The survey link was potentially received by an estimated 480 members of ISOQOL. Although the number of invitations actually received could not be determined, the ratio of invitations to respondents implies a response rate of approximately $30 \%$. The majority (63\%) of respondents had an excess of 10 years experience in HRQL research (Table 2). Thirty-six of the 40 items $(90 \%)$ were rated as 'essential' by at least half of the respondents, 27 (68\%) were rated as 'essential' by at least two-thirds of respondents, and all items (100\%) were rated as either 'essential' or 'desirable' by over three quarters of respondents (Table 3). These rankings changed when HRQL was a secondary outcome; with 12 items $(30 \%)$ then rated as 'essential' by over one-half of respondents, and 26 (65\%) 


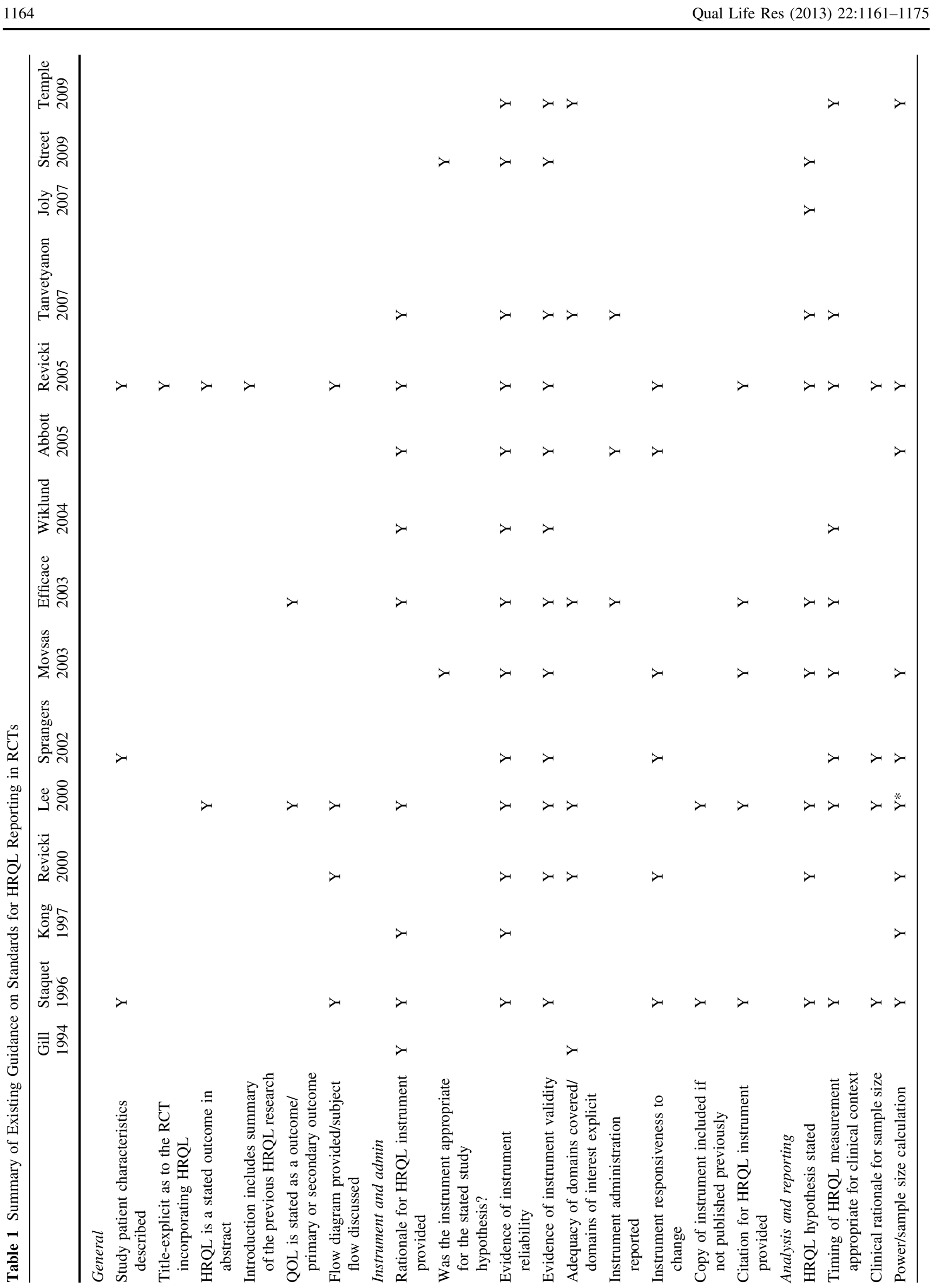

型 Springer 
Qual Life Res (2013) 22:1161-1175

1165

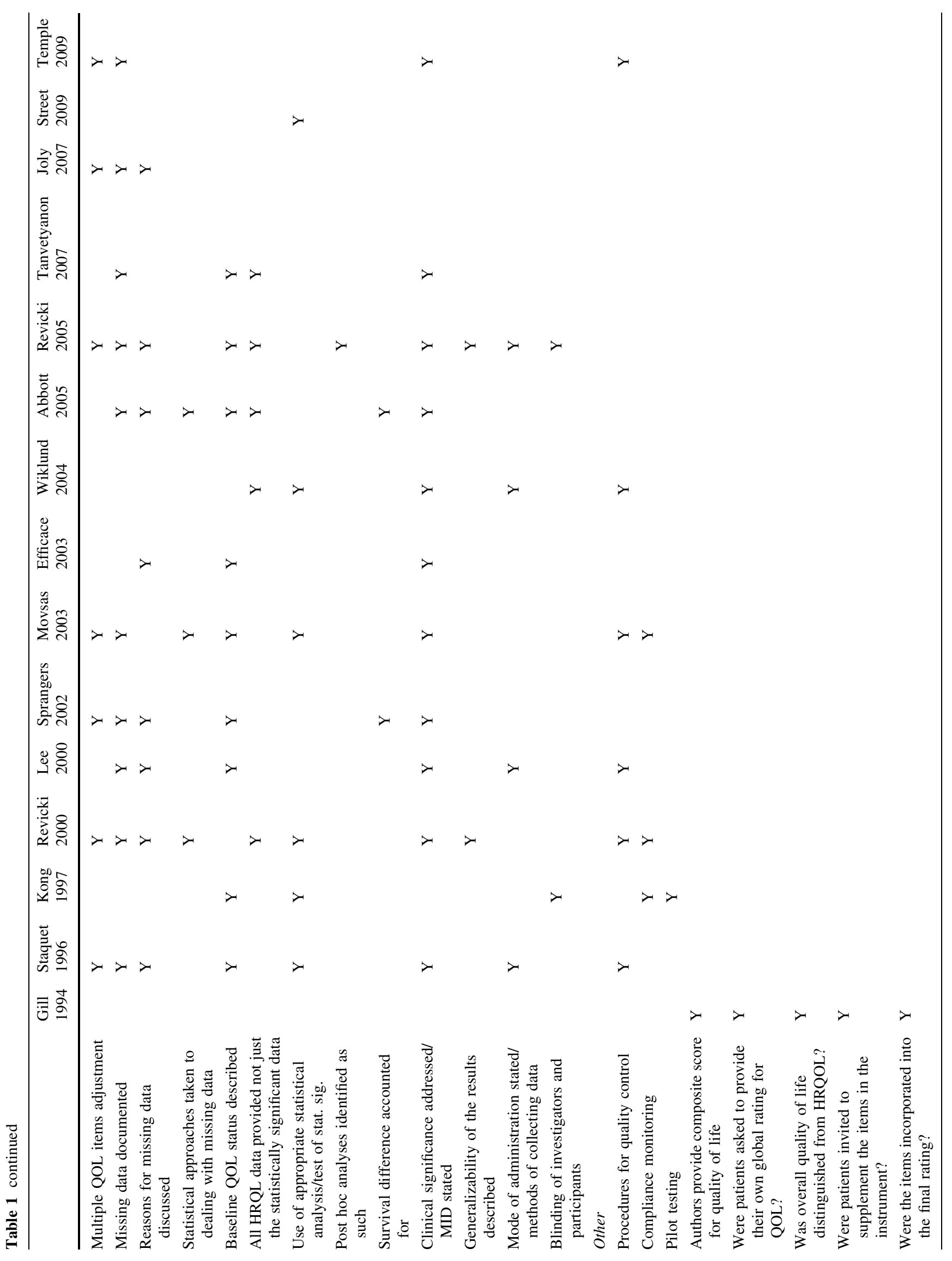

Springer 


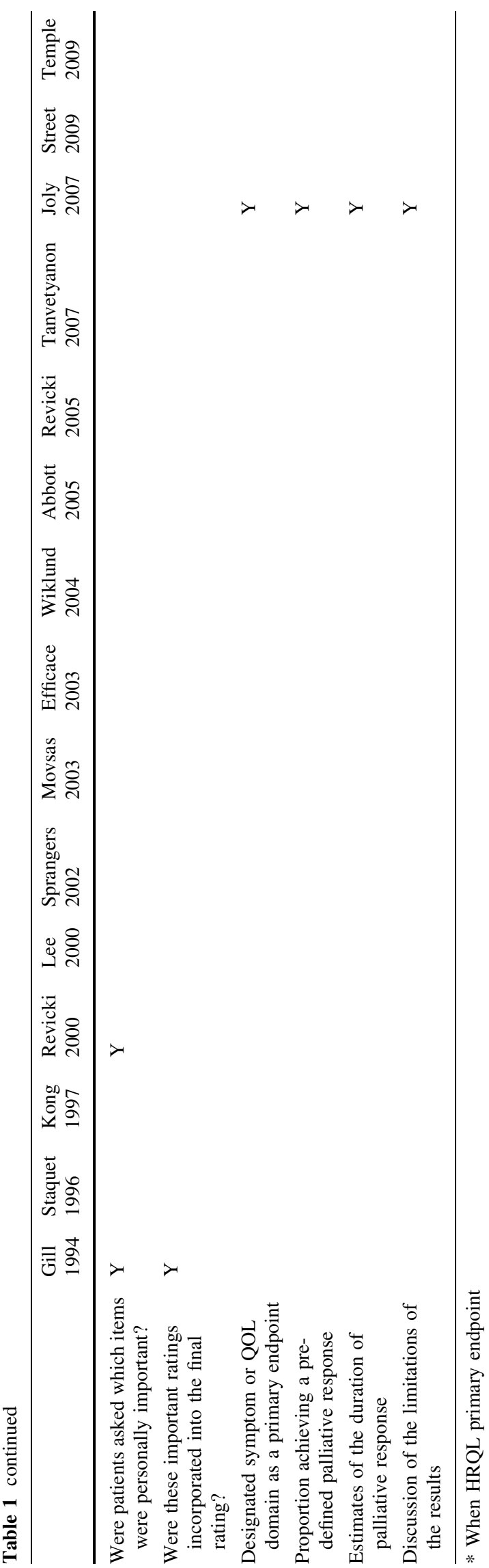

Table 2 Survey respondent demographics

$N(\%)$

Participant expertise $n=149$

HRQL assessment/psychology/sociology

$105(70.5)$

Frequent journal reviewer

$71(47.7)$

Clinical trials methods/analysis

Predominantly in psychometrics

Predominantly as clinician-scientist

$38(25.5)$

Policy/public health

$31(20.8)$

Predominantly as clinician

$19(12.8)$

Journal editor

Patient perspective

Regulator/health administrator

Other*

9 (6)

Career experience in $H R Q L$ research or related activities $n=148$

Currently undergrad/PhD student

Currently post doc

$<5$ years experience

5-10 years experience

$>10$ years experience

$93(62.8)$

* Other: PhD nursing student spent the past year critiquing articles, including studying CONSORT and other guidelines; Conducting literature reviews of treatment effects and HRQL endpoints; Systematic reviews and comparative effectiveness research; Associate Editor; Expertise in economic evaluations; Academic interest in performance and standards for interventions and implementation; Nurse Epidemiologist; Expertise in clinimetrics/psychometrics, hardly no experience in trials; Expertise in QOL assessment in communication disorders; Systematic reviewer Statistical editor; HRQL Instrument development and promulgation of use of these measures

rated as either 'essential' or 'desirable' by over three quarters of respondents (Table 3). Results were fairly consistent across subgroups (by expertise) in exploratory analyses. Notably however, a higher proportion of clinicians rated the reporting of the clinical significance of results as 'essential' (Fig. 1).

ISOQOL-recommended PRO reporting standards for randomized clinical trials

The results of the survey and feedback from the ISOQOL membership were used to develop a suite of reporting standards. While the survey focused specifically on the development of standards for use in studies in which HRQL is an outcome, these standards were acknowledged to be appropriate for PROs in general, outcomes such as single-item symptom evaluation, patient-reported measures of utility, or assessment of patient adherence and satisfaction (Table 4) [29]. 
Table 3 Survey responses

\begin{tabular}{|c|c|c|c|c|c|c|c|c|c|c|c|c|}
\hline \multirow[t]{3}{*}{ Item } & \multicolumn{6}{|c|}{ When HRQL is a primary outcome } & \multicolumn{6}{|c|}{ When HRQL is a secondary outcome } \\
\hline & \multirow[t]{2}{*}{ Rank } & \multirow[t]{2}{*}{$n$} & \multicolumn{4}{|c|}{ Percentage response } & \multirow[t]{2}{*}{ Rank } & \multirow[t]{2}{*}{$n$} & \multicolumn{4}{|c|}{ Percentage response } \\
\hline & & & Essential & Desirable & Optional & $\begin{array}{l}\text { Rarely } \\
\text { necessary }\end{array}$ & & & Essential & Desirable & Optional & $\begin{array}{l}\text { Rarely } \\
\text { necessary }\end{array}$ \\
\hline $\begin{array}{l}\text { HRQL should be } \\
\text { identified as an } \\
\text { outcome in the } \\
\text { abstract }\end{array}$ & 1 & 160 & 96.9 & 2.5 & 0.6 & 0.0 & 18 & 157 & 38.9 & 53.5 & 7.6 & 0.0 \\
\hline $\begin{array}{l}\text { The study patient } \\
\text { characteristics } \\
\text { should be described }\end{array}$ & 2 & 160 & 95.0 & 3.8 & 1.3 & 0.0 & 1 & 158 & 85.4 & 12.7 & 1.9 & 0.0 \\
\hline $\begin{array}{l}\text { The mode of } \\
\text { administration of the } \\
\text { HRQL tool and the } \\
\text { methods of } \\
\text { collecting data (e.g., } \\
\text { telephone, other) } \\
\text { should be described }\end{array}$ & 3 & 150 & 90.0 & 8.0 & 2.0 & 0.0 & 3 & 150 & 65.3 & 27.3 & 6.0 & 1.3 \\
\hline $\begin{array}{l}\text { The domains of } \\
\text { interest should be } \\
\text { explicitly stated and } \\
\text { be appropriate for } \\
\text { the disease/treatment } \\
\text { context }\end{array}$ & 4 & 154 & 89.6 & 9.1 & 0.6 & 0.6 & 10 & 153 & 56.2 & 37.9 & 5.2 & 0.7 \\
\hline $\begin{array}{l}\text { The clinical } \\
\text { significance of the } \\
\text { HRQL findings } \\
\text { should be discussed }\end{array}$ & 5 & 150 & 88.7 & 11.3 & 0.0 & 0.0 & 11 & 150 & 52.7 & 39.3 & 7.3 & 0.7 \\
\hline $\begin{array}{l}\text { The baseline HRQL } \\
\text { scores of study } \\
\text { participants should } \\
\text { be described }\end{array}$ & 6 & 151 & 86.8 & 10.6 & 2.6 & 0.0 & 8 & 152 & 58.6 & 28.9 & 10.5 & 2.0 \\
\hline $\begin{array}{l}\text { There should be } \\
\text { evidence of } \\
\text { appropriate } \\
\text { statistical analysis } \\
\text { and tests of } \\
\text { statistical } \\
\text { significance for each } \\
\text { HRQL hypothesis } \\
\text { tested }\end{array}$ & 7 & 148 & 85.8 & 12.2 & 0.7 & 1.4 & 7 & 148 & 59.5 & 33.1 & 6.1 & 1.4 \\
\hline $\begin{array}{l}\text { The HRQL hypothesis } \\
\text { should be stated and } \\
\text { should specify the } \\
\text { relevant HRQL } \\
\text { domain(s) }\end{array}$ & 8 & 153 & 85.0 & 13.1 & 1.3 & 0.7 & 17 & 153 & 39.2 & 47.7 & 11.8 & 1.3 \\
\hline $\begin{array}{l}\text { Reporting of who is } \\
\text { blinded to treatment } \\
\text { allocation in the trial } \\
\text { should be provided }\end{array}$ & 9 & 150 & 84.0 & 10.0 & 4.7 & 1.3 & 2 & 149 & 65.8 & 24.8 & 8.1 & 1.3 \\
\hline $\begin{array}{l}\text { The status of the } \\
\text { HRQL outcome as } \\
\text { either a primary or } \\
\text { secondary endpoint } \\
\text { should be stated }\end{array}$ & 10 & 160 & 83.1 & 15.6 & 1.3 & 0.0 & - & - & - & - & - & - \\
\hline $\begin{array}{l}\text { There should be cited } \\
\text { evidence of } \\
\text { instrument validity }\end{array}$ & 11 & 153 & 83.0 & 13.7 & 2.6 & 0.7 & 5 & 152 & 61.2 & 31.6 & 5.9 & 1.3 \\
\hline
\end{tabular}


Table 3 continued

\begin{tabular}{|c|c|c|c|c|c|c|c|c|c|c|c|c|}
\hline \multirow[t]{3}{*}{ Item } & \multicolumn{6}{|c|}{ When HRQL is a primary outcome } & \multicolumn{6}{|c|}{ When HRQL is a secondary outcome } \\
\hline & \multirow[t]{2}{*}{ Rank } & \multirow[t]{2}{*}{$n$} & \multicolumn{4}{|c|}{ Percentage response } & \multirow[t]{2}{*}{ Rank } & \multirow[t]{2}{*}{$n$} & \multicolumn{4}{|c|}{ Percentage response } \\
\hline & & & Essential & Desirable & Optional & $\begin{array}{l}\text { Rarely } \\
\text { necessary }\end{array}$ & & & Essential & Desirable & Optional & $\begin{array}{l}\text { Rarely } \\
\text { necessary }\end{array}$ \\
\hline $\begin{array}{l}\text { The rationale for } \\
\text { choice of the HRQL } \\
\text { instrument used } \\
\text { should be provided }\end{array}$ & 12 & 153 & 81.0 & 17.0 & 2.0 & 0.0 & 13 & 153 & 49.0 & 38.6 & 11.1 & 1.3 \\
\hline $\begin{array}{l}\text { There should be cited } \\
\text { evidence of } \\
\text { instrument reliability }\end{array}$ & 13 & 154 & 80.5 & 16.9 & 1.9 & 0.6 & 6 & 154 & 59.7 & 31.8 & 6.5 & 1.9 \\
\hline $\begin{array}{l}\text { HRQL hypotheses } \\
\text { should specify time } \\
\text { points at which the } \\
\text { HRQL outcomes } \\
\text { will be compared }\end{array}$ & 14 & 153 & 80.4 & 17.0 & 2.6 & 0.0 & 9 & 152 & 57.2 & 32.2 & 9.9 & 0.7 \\
\hline $\begin{array}{l}\text { The introduction } \\
\text { should contain a } \\
\text { summary of HRQL } \\
\text { research that is } \\
\text { relevant to the RCT }\end{array}$ & 15 & 159 & 79.2 & 15.7 & 4.4 & 0.6 & 35 & 157 & 21.0 & 53.5 & 23.6 & 1.9 \\
\hline $\begin{array}{l}\text { The authors should } \\
\text { discuss the } \\
\text { limitations of the } \\
\text { HRQL components } \\
\text { of the trial explicitly }\end{array}$ & 16 & 149 & 77.9 & 19.5 & 2.7 & 0.0 & 25 & 150 & 31.3 & 43.3 & 20.7 & 4.7 \\
\hline $\begin{array}{l}\text { There should be a } \\
\text { clinical rationale } \\
\text { provided for the } \\
\text { sample size (e.g., } \\
\text { anticipated effect } \\
\text { size) }\end{array}$ & 17 & 149 & 76.5 & 21.5 & 1.3 & 70.0 & 34 & 149 & 23.5 & 47.7 & 20.1 & 8.7 \\
\hline $\begin{array}{l}\text { A citation for the } \\
\text { original } \\
\text { development of the } \\
\text { HRQL instrument } \\
\text { should be provided }\end{array}$ & 18 & 154 & 76.0 & 18.8 & 4.5 & 0.6 & 4 & 154 & 64.3 & 26.6 & 7.8 & 1.3 \\
\hline $\begin{array}{l}\text { Statistical approaches } \\
\text { for dealing with } \\
\text { missing data should } \\
\text { be explicitly stated }\end{array}$ & 19 & 149 & 75.8 & 18.1 & 6.0 & 0.0 & 16 & 151 & 43.7 & 35.1 & 17.9 & 3.3 \\
\hline $\begin{array}{l}\text { There should be a } \\
\text { power/sample size } \\
\text { calculation relevant } \\
\text { to the HRQL } \\
\text { outcome }\end{array}$ & 20 & 153 & 75.8 & 17.6 & 5.2 & 1.3 & 36 & 152 & 17.8 & 41.4 & 24.3 & 16.4 \\
\hline $\begin{array}{l}\text { Any post hoc analyses } \\
\text { of HRQL data } \\
\text { should be identified }\end{array}$ & 21 & 146 & 74.7 & 19.9 & 3.4 & 2.1 & 12 & 145 & 51.0 & 33.8 & 13.1 & 2.1 \\
\hline $\begin{array}{l}\text { The intended HRQL } \\
\text { data collection } \\
\text { schedule should be } \\
\text { provided }\end{array}$ & 22 & 151 & 71.5 & 23.2 & 4.6 & 0.7 & 14 & 151 & 48.3 & 36.4 & 13.2 & 2.0 \\
\hline $\begin{array}{l}\text { The generalizability of } \\
\text { the HRQL results } \\
\text { should be described }\end{array}$ & 23 & 148 & 69.6 & 27.7 & 2.7 & 0.0 & 21 & 148 & 36.5 & 42.6 & 18.9 & 2.0 \\
\hline
\end{tabular}


Table 3 continued

\begin{tabular}{|c|c|c|c|c|c|c|c|c|c|c|c|c|}
\hline \multirow[t]{3}{*}{ Item } & \multicolumn{6}{|c|}{ When HRQL is a primary outcome } & \multicolumn{6}{|c|}{ When HRQL is a secondary outcome } \\
\hline & \multirow[t]{2}{*}{ Rank } & \multirow[t]{2}{*}{$n$} & \multicolumn{4}{|c|}{ Percentage response } & \multirow[t]{2}{*}{ Rank } & \multirow[t]{2}{*}{$n$} & \multicolumn{4}{|c|}{ Percentage response } \\
\hline & & & Essential & Desirable & Optional & $\begin{array}{l}\text { Rarely } \\
\text { necessary }\end{array}$ & & & Essential & Desirable & Optional & $\begin{array}{l}\text { Rarely } \\
\text { necessary }\end{array}$ \\
\hline $\begin{array}{l}\text { The extent of missing } \\
\text { HRQL data should } \\
\text { be documented at } \\
\text { each time point }\end{array}$ & 24 & 151 & 69.5 & 21.9 & 7.3 & 1.3 & 26 & 151 & 30.5 & 45.0 & 21.2 & 3.3 \\
\hline $\begin{array}{l}\text { Hypotheses should } \\
\text { specify the direction } \\
\text { of change of HRQL } \\
\text { outcomes }\end{array}$ & 25 & 152 & 69.1 & 23.7 & 5.9 & 1.3 & 15 & 152 & 45.4 & 39.5 & 13.2 & 2.0 \\
\hline $\begin{array}{l}\text { The title of the paper } \\
\text { should be explicit as } \\
\text { to the RCT including } \\
\text { an HRQL outcome }\end{array}$ & 26 & 159 & 67.9 & 23.9 & 7.5 & 0.6 & 39 & 157 & 9.6 & 45.9 & 38.9 & 5.7 \\
\hline $\begin{array}{l}\text { There should be cited } \\
\text { evidence of } \\
\text { instrument } \\
\text { responsiveness to } \\
\text { change }\end{array}$ & 27 & 150 & 66.7 & 26.0 & 6.7 & 0.7 & 20 & 150 & 36.7 & 48.0 & 13.3 & 2.0 \\
\hline $\begin{array}{l}\text { The manner in which } \\
\text { multiple } \\
\text { comparisons have } \\
\text { been addressed } \\
\text { should be provided }\end{array}$ & 28 & 149 & 65.8 & 29.5 & 2.7 & 2.0 & 19 & 150 & 38.0 & 43.3 & 16.0 & 2.7 \\
\hline $\begin{array}{l}\text { The HRQL results } \\
\text { should be discussed } \\
\text { in the context of the } \\
\text { other clinical trial } \\
\text { outcomes }\end{array}$ & 29 & 151 & 62.9 & 31.8 & 5.3 & 0.0 & 31 & 150 & 27.3 & 54.0 & 16.7 & 2.0 \\
\hline $\begin{array}{l}\text { The reasons for } \\
\text { missing HRQL data } \\
\text { should be discussed }\end{array}$ & 30 & 150 & 62.7 & 31.3 & 4.7 & 1.3 & 32 & 150 & 24.0 & 49.3 & 22.7 & 4.0 \\
\hline $\begin{array}{l}\text { Results should be } \\
\text { reported for all } \\
\text { HRQL domains and } \\
\text { items identified by } \\
\text { the reference } \\
\text { instrument (i.e., not } \\
\text { just those that are } \\
\text { statistically } \\
\text { significant) }\end{array}$ & 31 & 150 & 62.7 & 25.3 & 9.3 & 2.7 & 24 & 150 & 32.0 & 42.7 & 20.0 & 5.3 \\
\hline $\begin{array}{l}\text { Evidence should be } \\
\text { provided that the } \\
\text { reported HRQL } \\
\text { results were } \\
\text { prespecified in the } \\
\text { protocol }\end{array}$ & 32 & 143 & 61.5 & 25.9 & 8.4 & 4.2 & 28 & 144 & 29.9 & 42.4 & 18.8 & 9.0 \\
\hline $\begin{array}{l}\text { The data collection } \\
\text { schedule should be } \\
\text { justified as being } \\
\text { appropriate for the } \\
\text { clinical context }\end{array}$ & 33 & 148 & 59.5 & 32.4 & 6.1 & 2.0 & 22 & 147 & 33.3 & 45.6 & 16.3 & 4.8 \\
\hline
\end{tabular}


Table 3 continued

\begin{tabular}{|c|c|c|c|c|c|c|c|c|c|c|c|c|}
\hline \multirow[t]{3}{*}{ Item } & \multicolumn{6}{|c|}{ When HRQL is a primary outcome } & \multicolumn{6}{|c|}{ When HRQL is a secondary outcome } \\
\hline & \multirow[t]{2}{*}{ Rank } & \multirow[t]{2}{*}{$n$} & \multicolumn{4}{|c|}{ Percentage response } & \multirow[t]{2}{*}{ Rank } & \multirow[t]{2}{*}{$n$} & \multicolumn{4}{|c|}{ Percentage response } \\
\hline & & & Essential & Desirable & Optional & $\begin{array}{l}\text { Rarely } \\
\text { necessary }\end{array}$ & & & Essential & Desirable & Optional & $\begin{array}{l}\text { Rarely } \\
\text { necessary }\end{array}$ \\
\hline $\begin{array}{l}\text { A flow diagram or a } \\
\text { description of the } \\
\text { allocation of } \\
\text { participants and } \\
\text { those lost to follow- } \\
\text { up should be } \\
\text { provided for HRQL } \\
\text { specifically }\end{array}$ & 34 & 151 & 58.9 & 25.8 & 11.9 & 3.3 & 38 & 150 & 12.7 & 41.3 & 32.0 & 14.0 \\
\hline $\begin{array}{l}\text { Where survival is a } \\
\text { relevant trial } \\
\text { outcome, HRQL } \\
\text { analysis should } \\
\text { account for survival } \\
\text { differences between } \\
\text { treatment groups }\end{array}$ & 35 & 138 & 55.1 & 36.2 & 6.5 & 2.2 & 23 & 138 & 34.1 & 40.6 & 19.6 & 5.8 \\
\hline $\begin{array}{l}\text { The time window for } \\
\text { valid HRQL } \\
\text { responses should be } \\
\text { specified }\end{array}$ & 36 & 147 & 52.4 & 36.7 & 10.2 & 0.7 & 27 & 145 & 30.3 & 46.2 & 21.4 & 2.1 \\
\hline $\begin{array}{l}\text { Quality control } \\
\text { procedures for } \\
\text { HRQL data should } \\
\text { be provided }\end{array}$ & 37 & 146 & 48.6 & 35.6 & 12.3 & 3.4 & 29 & 146 & 28.1 & 36.3 & 27.4 & 8.2 \\
\hline $\begin{array}{l}\text { The proportion of } \\
\text { patients achieving } \\
\text { pre-defined } \\
\text { responder definitions } \\
\text { should be provided }\end{array}$ & 38 & 144 & 47.2 & 30.6 & 18.8 & 3.5 & 33 & 143 & 23.8 & 42.0 & 28.0 & 6.3 \\
\hline $\begin{array}{l}\text { A copy of the } \\
\text { instrument should be } \\
\text { included if it has not } \\
\text { been published } \\
\text { previously }\end{array}$ & 39 & 153 & 44.4 & 31.4 & 16.3 & 7.8 & 30 & 153 & 28.1 & 28.1 & 32.0 & 11.8 \\
\hline $\begin{array}{l}\text { The report should state } \\
\text { how HRQL data } \\
\text { collection protocols } \\
\text { were monitored }\end{array}$ & 40 & 149 & 39.6 & 36.9 & 17.4 & 6.0 & 37 & 147 & 17.7 & 41.5 & 26.5 & 14.3 \\
\hline
\end{tabular}

\section{Discussion}

Synthesis of a systematic review of the literature and survey of the ISOQOL membership has informed the development of ISOQOL reporting guidelines for PROs in the primary publication of RCTs. More specifically, we provide reporting standards for RCTs reporting any PRO outcome and make additional recommendations for those trials in which PROs are the primary outcome. This work will be used to inform an official CONSORT extension for PRO reporting in RCTs.

While current CONSORT guidelines for trial reporting include several standards that apply to HRQL and PRO endpoints, the Task Force felt that further clarification was needed [11]. For example, the 2010 CONSORT guidance states that 'a table showing baseline demographic and clinical characteristics for each group should be reported.' However, neither the guideline nor the explanatory document explicitly recommends that publications report baseline values relating to the primary or secondary PRO endpoints with a measure of their variability. There is also a lack of clarity about the appropriate level of detail required for reporting missing outcome data, which is particularly critical when interpreting PRO trial endpoints.

The new ISOQOL reporting guidelines have important implications beyond improved documentation of trial 
Rationale for Choice of HRQL instrument should be provided

Cited evidence of validity and reliability

\section{Mode of admin.\& methods for collecting data should be described}

Statistical approaches for dealing with missing data should be explicitly stated

\section{Extent of missing data} should be discussed

al significance of the HRQL findings should be discussed

The limitations of the HRQL components of the trial should be explicitly discussed

HRQL results should be discussed in the context of other trial outcomes

HRQL should be described as an outcome in the abstract

\section{Percent of Respondents}

25

50

75

100

Psych./Soc.Scientist

Trials methodologist

Journal

Policy maker

Clinician

Psych./Soc.Scientist

Trials methodologist Journal

Policy maker

Clinician

Psych./Soc.Scientist

Trials methodologist Journal

Policy maker

Clinician

Psych./Soc.Scientist

Trials methodologist Journal

Policy maker

Clinician

Psych./Soc.Scientist

Trials methodologist Journal

Policy maker

Clinician

Psych./Soc.Scientist

Trials methodologist Journal Policy maker

Clinician

Psych./Soc.Scientist

Trials methodologist Journal Policy maker

Clinician

Psych./Soc.Scientist

Trials methodologist Journal

Policy maker

Clinician

Psych./Soc.Scientist

Trials methodologist Journal

Policy maker
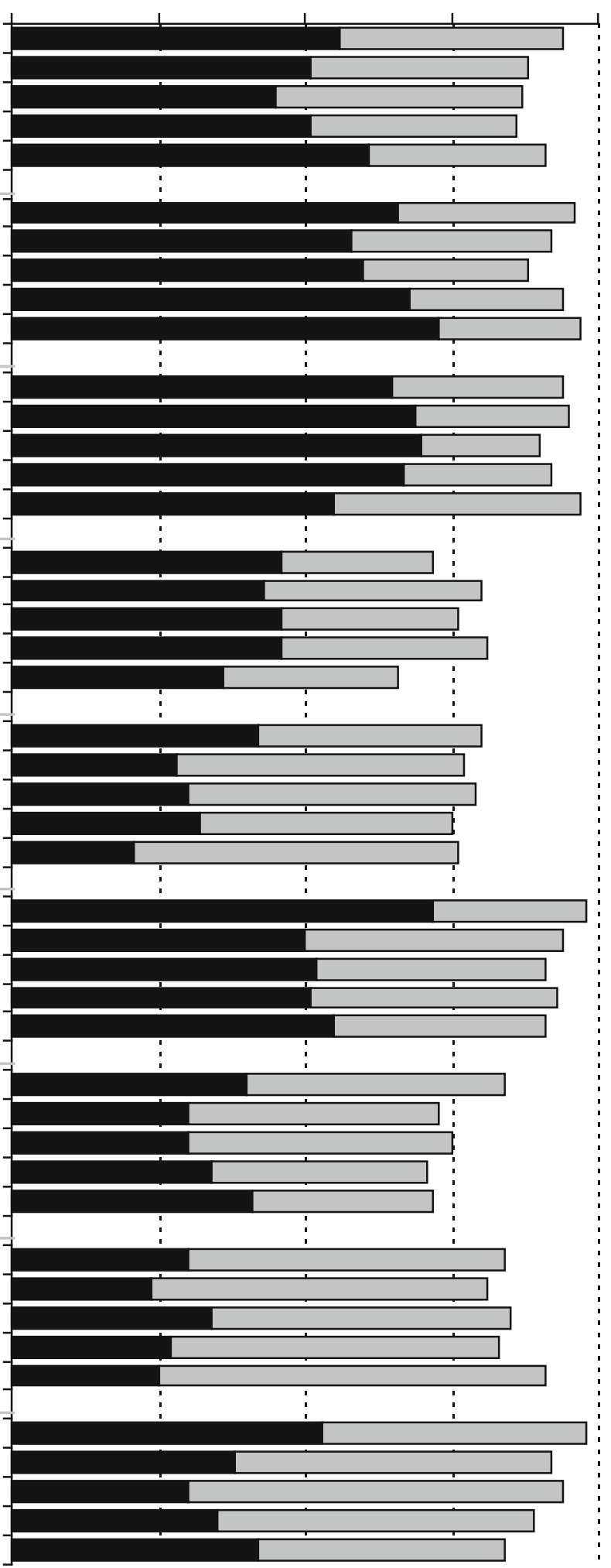

Reporting Standard: Essential $\square$ Desirable $\square$

Fig. 1 Survey response by participant expertise for selected reporting standards 
outcomes if they also act to influence the design of future trials with PRO measures. Evidence for this type of impact is apparent in other areas; since the publication of the original CONSORT guidance, there is now work being undertaken to provide trialists and clinicians with standards for trial protocol development [30]. Future international collaborations among stakeholder groups could include similar efforts for informing trial design with respect to PROs.

The reality of journal word limits may constrain comprehensive reporting of all of the ISOQOL-recommended standards, particularly when the PRO is a secondary study outcome. A recent review of HRQL reporting in clinical trials across a range of clinical areas showed that HRQL was a secondary outcome in $75 \%$ of studies (594/794) [10]. Without transparent reporting of these secondary outcomes, it may be impossible for readers or consumers to assess the quality of the results and identify any potential bias. Journal web appendices are a relatively new option that may, in part, alleviate this problem.

The process used to establish PRO reporting standards for RCTs has a number of strengths. The candidate reporting standards were identified through a formal systematic review, and the guidance was developed through a comprehensive iterative process with multiple opportunities for feedback from the experts within the ISOQOL membership who have a collective, extensive international experience in this field. A modified Delphi approach was used to assess member opinions and to reach consensus on a final list of reporting standards; this approach is consistent with the development of other CONSORT guidelines [31]. The consistency of endorsement of each standard across different areas of respondents' expertise is an indication of the reliability of the survey data. One notable, but perhaps not surprising, exception to this consistency is that a higher proportion of clinicians rated reporting of the clinical significance of results as essential, demonstrating the potential importance of this item for translation of HRQL results into practice.

The interpretation of the survey results and the consensus recommendations are limited in some ways including the use of the online survey method to poll ISOQOL members. Although we attempted to invite all ISOQOL members to respond, it is unknown how many members actually received or viewed the email, and an accurate response rate cannot be calculated. Likewise, the 'view rate' of email invitations cannot be calculated due to the anonymous nature of the research method [32]. Further, it is likely that some ISOQOL members felt that they did not have sufficient expertise or interest in this academic topic to respond, and regrettably, we did not allow such a response option in our design. Likewise, it is possible that some respondents with only passing interest in the topic may have completed the survey without sufficient knowledge or experience in designing, analyzing, reporting, or interpreting RCTs. With regard to the latter possibility, however, we note that the majority of respondents did report having significant expertise in HRQL research. Again, the consistency of responses across expertise groups suggests reliability of the findings. Although there was clearly underlying variation in ISOQOL member opinions, particularly when HRQL is a secondary outcome, the systematic approach to the data by the Task Force led to final recommended standards that are in keeping with the majority view of the member survey results for each standard considered in the survey. Finally, while the literature search and survey focussed on HRQL standards, rather than all PROs, the consensus process endorsed the expanded scope.

\section{Conclusions and implications}

The results of this literature review and survey enabled an ISOQOL Task Force to arrive at consensus regarding recommended standards for reporting PROs in publications of randomized clinical trials. These recommendations were developed with input from the membership and endorsed by the ISOQOL leadership and have now been used in conjunction with information from other key stakeholders to inform a Consensus meeting and the development of a new CONSORT extension to guide the reporting of PROs [11, 31]. Knowledge transfer activities including endorsement from major journals will be crucial to the success of the CONSORT extension. This guidance will need to be evaluated with respect to its impact on the quality of PRO reporting, and we note that no formal evaluation of the past published recommended reporting standards has been undertaken. In keeping with promoting effective knowledge translation, the ISOQOL standards themselves will be available through the ISOQOL website and related publications and will serve as continued guidance for RCT reporting that reflects the ISOQOL consensus.

In sum, consumers of PRO data (including HRQL), who may be healthcare information providers, clinicians, policy makers, and patients themselves, should demand highquality, well-reported data from RCTs. Likewise, organizations that fund clinical trials research should also be aware of issues relevant to PRO reporting and should require standardized reporting to facilitate use of PRO data in clinical practice. These consensus guidelines are an important component of establishing standards that will lead, through effective knowledge translation processes, to improved reporting practices. 


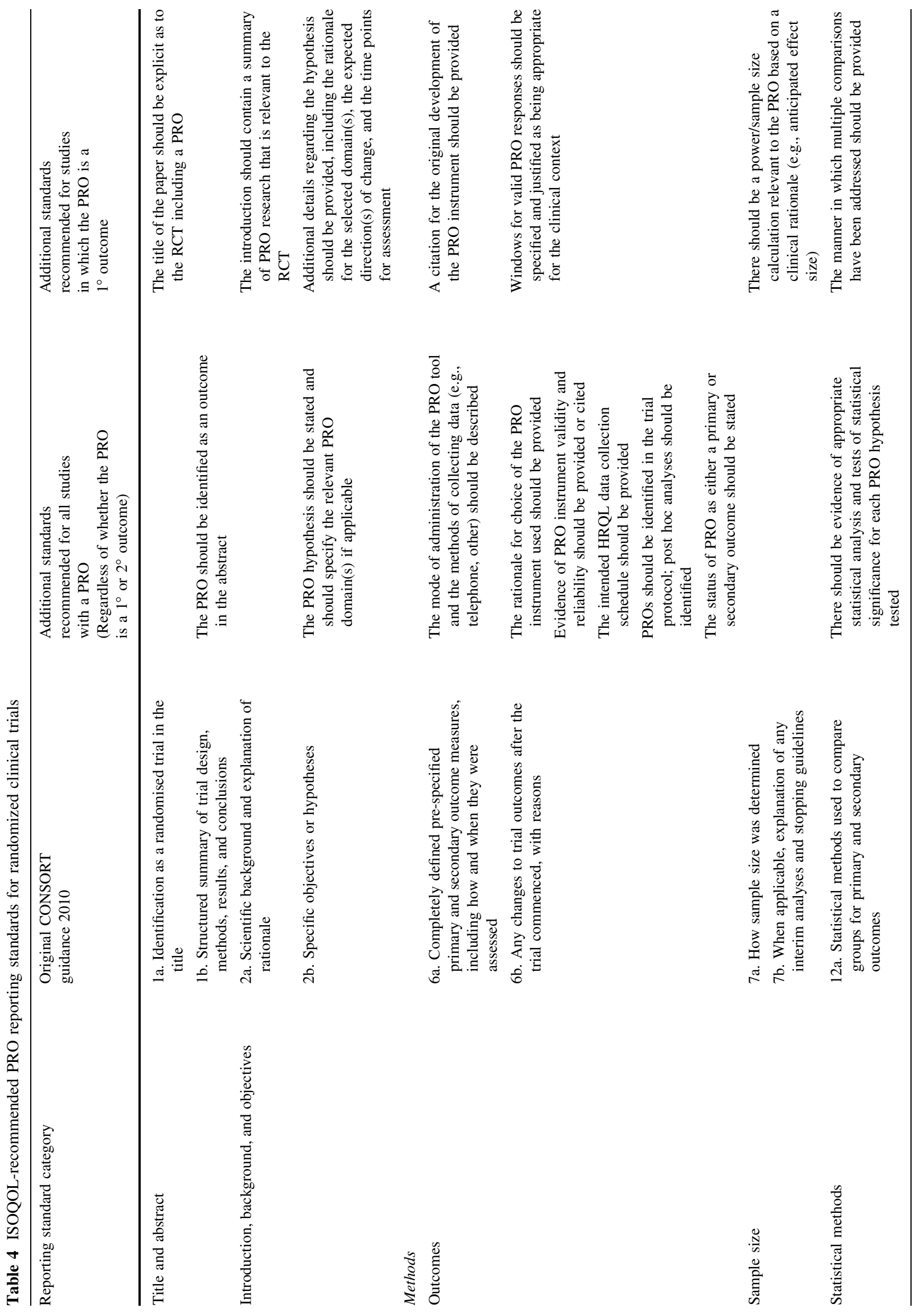




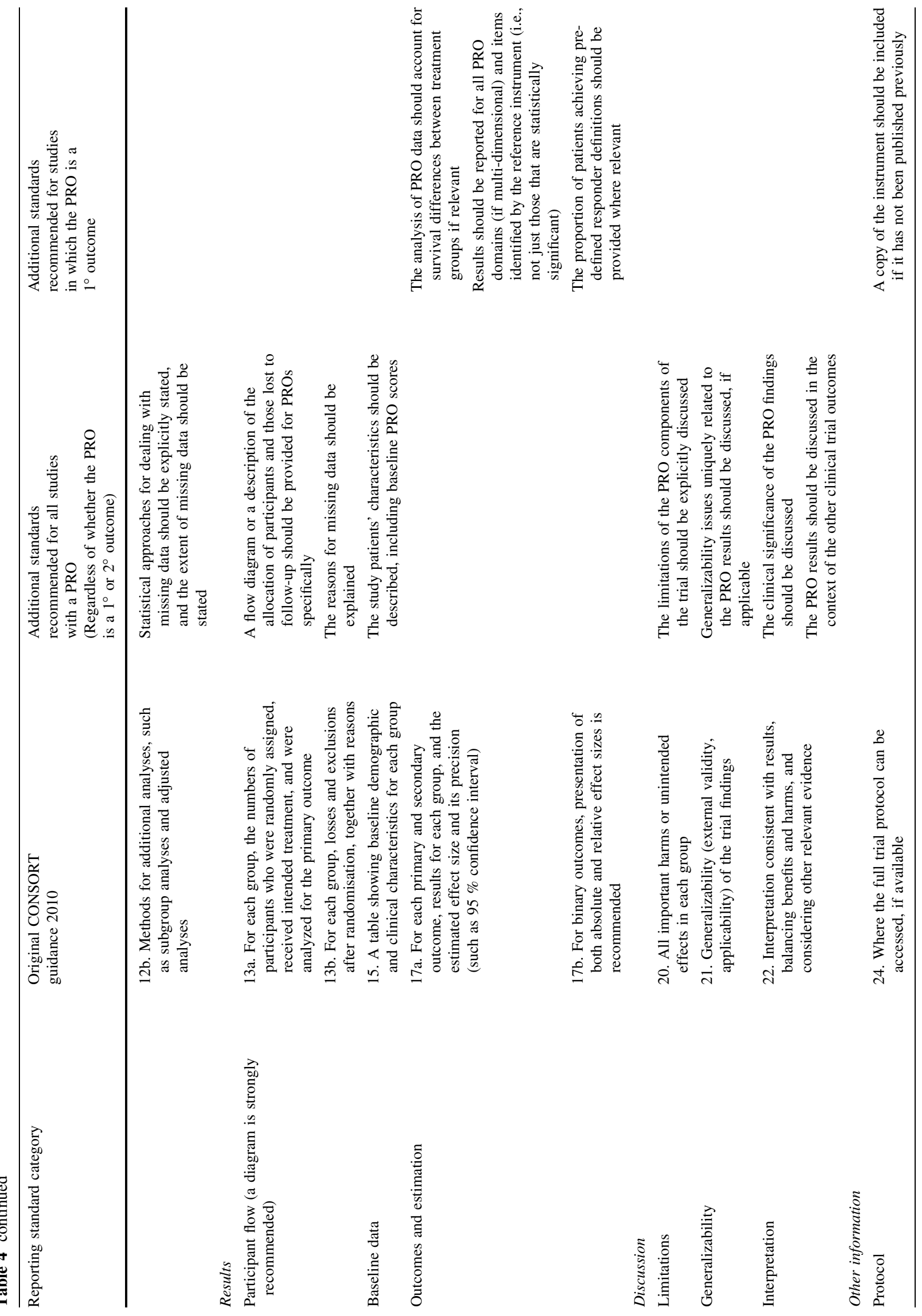


Open Access This article is distributed under the terms of the Creative Commons Attribution License which permits any use, distribution, and reproduction in any medium, provided the original author(s) and the source are credited.

\section{References}

1. Calvert M, Freemantle N (2004) Research note: Use of healthrelated quality of life in prescribing research, part 1. Journal of Clinical Pharmacy \& Therapeutics.

2. Brundage, M., Bass, B., Jolie, R., \& Foley, K. (2011). A knowledge translation challenge: Clinical use of quality of life data from cancer clinical trials. Quality of Life Research, 20(7), 979-985.

3. Brundage, M., Leis, A., Bezjak, A., Feldman-Stewart, D., Degner, L., Velji, K., et al. (2003). Cancer patients' preferences for communicating clinical trial quality of life information: A qualitative study. Quality of Life Research, 12(4), 395-404.

4. Lipscomb, J., Gotay, C. C., \& Snyder, C. F. (2007). Patientreported outcomes in cancer: A review of recent research and policy initiatives. CA: A Cancer Journal for Clinicians, 57(5), 278-300.

5. Osoba, D. (2005). The clinical value and meaning of healthrelated quality-of-life outcomes in oncology. In J. Lipscomb, C. C. Gotay, \& C. Snyder (Eds.), Outcomes assessment in cancer (1st ed., pp. 386-405). Cambridge: Cambridge University Press.

6. Lemieux, J., Goodwin, P. J., Bordeleau, L. J., Lauzier, S., \& Theberge, V. (2011). Quality-of-life measurement in randomized clinical trials in breast cancer: An updated systematic review (2001-2009). Journal of the National Cancer Institute, 103(3), 178-231.

7. Efficace, F., Bottomley, A., Osoba, D., Gotay, C., Flechtner, H., D'haese, S., et al. (2003). Beyond the development of healthrelated quality-of-life (HRQOL) measures: A checklist for evaluating HRQOL outcomes in cancer clinical trials-does HRQOL evaluation in prostate cancer research inform clinical decision making? Journal of Clinical Oncology, 21(18), 3502-3511.

8. Lee, C. W., \& Chi, K. N. (2000). The standard of reporting of health-related quality of life in clinical cancer trials. Journal of Clinical Epidemiology, 53(5), 451-458.

9. Staquet, M., Berzon, R., Osoba, D., \& Machin, D. (1996). Guidelines for reporting results of quality of life assessments in clinical trials. Quality of Life Research, 5(5), 496-502.

10. Brundage, M., Bass, B., Davidson, J., Queenan, J., Bezjak, A., Ringash, J., et al. (2011). Patterns of reporting health-related quality of life outcomes in randomized clinical trials: Implications for clinicians and quality of life researchers. Quality of Life Research, 20, 653-664.

11. Consolidated Standards of Reporting Trials (CONSORT) 2010. http://www.consort-statement.org.home.

12. Schulz, K. F., Altman, D. G., Moher, D., \& CONSORT Group. (2010). CONSORT 2010 statement: Updated guidelines for reporting parallel group randomized trials. Annals of Internal Medicine, 152(11), 726-732.

13. MRC Hubs for Trials Methodology Research. http://www. methodologyhubs.mrc.ac.uk/about_us/hubs.aspx.

14. International Society for Quality of Life Research (ISOQOL) http://www.isoqol.org/2011.
15. Survey Monkey-Survey Development Software http://www. surveymonkey.com/.

16. MICROSOFT Excel software http://office.microsoft.com/en-ca/ excel/.

17. Abbott, J., \& Hart, A. (2005). Measuring and reporting quality of life outcomes in clinical trials in cystic fibrosis: A critical review. Health \& Quality of Life Outcomes, 3, 19.

18. Gill, T., \& Feinstein, A. R. (1994). A critical appraisal of the quality of quality-of-life measurements. JAMA, 272(8), 619-626.

19. Joly, F., Vardy, J., Pintilie, M., \& Tannock, I. F. (2007). Quality of life and/or symptom control in randomized clinical trials for patients with advanced cancer. Annals of Oncology, 18(12), 1935-1942.

20. Movsas, B. (2003). Quality of life in oncology trials: A clinical guide. Seminars in Radiation Oncology, 13(3), 235-247.

21. Street, J., Lenehan, B., \& Fisher, C. (2009). The quality of quality of life publications in the spinal literature: Are we getting any better? Journal of Neurosurgery Spine, 11(5), 512-517.

22. Tanvetyanon, T., Soares, H. P., Djulbegovic, B., Jacobsen, P. B., \& Bepler, G. (2007). A systematic review of quality of life associated with standard chemotherapy regimens for advanced non-small cell lung cancer. Journal of Thoracic Oncology: Official Publication of the International Association for the Study of Lung Cancer, 2(12), 1091-1097.

23. Temple, L., Fuzesi, S., \& Patil, S. (2009). The importance of determining quality of life in clinical trials. Surgery, 145(6), $622-626$.

24. Wiklund, I. (2004). Assessment of patient-reported outcomes in clinical trials: The example of health-related quality of life. Fundamental \& Clinical Pharmacology, 18(3), 351-363.

25. Kong, S., \& Gandhi, S. (1997). Methodologic assessments of quality of life measures in clinical trials. The Annals of Pharmacotherapy, 31, 830-836.

26. Revicki, D. A., Osoba, D., Fairclough, D., Barofsky, I., Berzon, R., Leidy, N. K., et al. (2000). Recommendations on healthrelated quality of life research to support labeling and promotional claims in the United States. Quality of Life Research, 9(8), 887-900.

27. Revicki, D. A. (2005). Reporting analyses for clinical trials. In P. Fayers \& R. D. Hays (Eds.), Assessing quality of life in clinical trials (2nd ed.). New York: Oxford University Press.

28. Sprangers, M. A., Moinpour, C. M., Moynihan, T. J., Patrick, D. L., \& Revicki, D. A. (2002). Assessing meaningful change in quality of life over time: A users' guide for clinicians. Mayo Clinic Proceedings, 77(6), 561-571.

29. European Medicines Agency. (2005). Reflection paper on the regulatory guidance for the use of health-related quality of life (HRQL) measures in the evaluation of medicinal products.

30. The SPIRIT Initiative (Standard Protocol Items: Recommendations for Interventional trials). (2011). http://www.equatornetwork.org/resource-centre/library-of-health-research-reporting/ reporting-guidelines-under-development/.

31. Moher, D., Schulz, K. F., Simera, I., \& Altman, D. G. (2010). Guidance for developers of health research reporting guidelines. PLoS Medicine/Public Library of Science, 7(2), e1000217.

32. Eysenbach, G. (2004). Improving the quality of Web surveys: The checklist for reporting results of internet E-surveys (CHERRIES). Journal of Medical Internet Research, 6(3), e34. 